\title{
As Crenças sobre a Homossexualidade e o Preconceito contra Homossexuais no Ambiente de Trabalho
}

\author{
Annelyse dos Santos Lira Soares Pereira \\ Faculdade Maurício de Nassau, João Pessoa, PB, Brasil \\ Susana Maria Pires da Silva Dias \\ Instituto Universitário de Lisboa, Lisboa, Portugal \\ Tiago Jessé Souza de Lima ${ }^{1}$ \\ Luana Elayne Cunha de Souza \\ Universidade de Fortaleza, Fortaleza, CE, Brasil
}

\begin{abstract}
Resumo
O presente estudo tem por objetivo entender o preconceito contra homossexuais no ambiente de trabalho a partir das crenças que os trabalhadores heterossexuais têm sobre a natureza da homossexualidade. Levantamos a hipótese de que essas crenças estão na base da expressão de atitudes e comportamentos homofóbicos no ambiente de trabalho. Tomaram parte neste estudo 169 trabalhadores heterossexuais, de cinco empresas portuguesas de grande porte, de ambos os sexos, com idade média de 32,8 anos ( $D P=$ $8,29)$, sendo a maioria do sexo feminino $(68 \%)$. Os resultados obtidos mostraram que o preconceito contra homossexuais no ambiente de trabalho se expressa pela maior adesão a crenças ético-morais como explicação da natureza da homossexualidade. Os homens apresentam maior rejeição à proximidade $\mathrm{e}$ expressão de mais emoções negativas em relação aos homossexuais do que as mulheres. A discussão aborda a importância de crenças sobre a natureza dos grupos sociais para melhor se compreender os princípios organizadores do preconceito e da discriminação contra grupos minoritários no contexto de relações laborais.
\end{abstract}

Palavras-chaves: Crenças, homossexualidade, preconceito, trabalho.

\section{Beliefs about Homosexuality and the Prejudice against Homosexuals in the Workplace}

\begin{abstract}
This study aims to understand the prejudice against homosexuals in the workplace analyzing the role played by individuals' beliefs about the nature of homosexuality. We hypothesize that beliefs about the nature of homosexuality underlie the expression of homophobic attitudes and discriminatory behavior in the workplace. Take part in this study 169 heterosexual workers from five Portuguese companies, of both genders (mostly part of them are female, $68 \%$ ) with a mean age of 32.8 years $(S D=8.29)$. The results showed that greater individuals' support for ethical and moral beliefs about the nature of homosexuality predict prejudice against homosexuals in the workplace. Moreover, men expressed a higher rejection of proximity and expressed more negative emotions towards homosexuals than women participants express. The discussion addresses the importance of beliefs about the nature of social groups to
\end{abstract}

Endereço para correspondência: Universidade de Fortaleza, Departamento de Psicologia, Av. Washington Soares, 1321, Edson Queiroz, Fortaleza, CE, Brasil 60811-905. E-mail: tiago.souzalima@hotmail.com 
better understand the organizing principles of prejudice and discrimination against minority groups in the context of labor relations.

Keywords: Beliefs, homosexuality, prejudice, workplace.

\section{Las Creencias sobre la Homosexualidad y o Prejuicio contra los Homosexuales en el Lugar de Trabajo}

\section{Resumen}

Este estudio tiene como objetivo comprender el prejuicio contra los homosexuales en el lugar de trabajo a partir de las creencias que los empleados heterosexuales tienen sobre la naturaleza de la homosexualidad. La hipótesis testada es que estas creencias son la base de la expresión de actitudes y comportamientos homófobos en el lugar de trabajo. Participaron en este estudio 169 trabajadores heterosexuales, empleados en cinco grandes empresas portuguesas, de ambos sexos, en su mayoría mujeres (68\%), con una edad media de 32,8 años $(S D=8.29)$. Los resultados mostraron que los prejuicios contra los homosexuales en el lugar de trabajo están relacionados con una mayor adhesión a las creencias éticas y morales como una explicación de la naturaleza de la homosexualidad. Los hombres tienen un mayor rechazo de la cercanía y mayor expresión de emociones negativas hacia los homosexuales, comparado a las mujeres. La conclusión discute la importancia de las creencias acerca de la naturaleza de los grupos sociales para comprender mejor los principios de organización de los prejuicios y de la discriminación contra los grupos minoritarios en el contexto de relaciones laborales.

Palabras claves: Creencias, homosexualidad, prejuicio, trabajo.

O tema da homossexualidade tem sido alvo de um forte debate social, quer ao nível da igualdade de direitos humanos, como é exemplo o casamento civil e a adoção de filhos por pais homoafetivos, quer no combate ao preconceito e discriminação contra os homossexuais nos vários contextos sociais. Nas organizações, onde o profissionalismo é considerado um princípio normativo para sustentar e promover um ambiente de trabalho coeso em prol de objetivos econômicos (Mizzi, 2013), o preconceito contra o homossexual ainda é forte.

Diversos estudos (Eliason, Dejoseph, Dibble, Deevey, \& Chinn, 2011; Ferreira, 2007; Williams \& Guiffre, 2011) descrevem as experiências vivenciadas por homossexuais no ambiente de trabalho, destacando os problemas que estes enfrentam para se manterem empregados e para obterem sucesso na carreira profissional, dentre eles, destacam-se a discriminação, o assédio verbal, os estereótipos negativos e os estigmas sociais. Tais problemas contribuem para que os indivíduos escondam sua identidade sexual, a fim de não serem prejudicados em sua carreira, e trazem prejuízos para a produtividade do funcionário e da empresa à medida que a revelação da identidade sexual muitas vezes leva a dificuldades de relacionamento entre os empregados (Ferreira, 2007).

Em face desse contexto, compreender que fatores sustentam o preconceito contra os homossexuais no ambiente de trabalho parece ser uma questão de grande relevância social. É possível que a discriminação e o preconceito contra os homossexuais se embasem em um sistema de representações que envolvam crenças e valores preconceituosos acerca da natureza da homossexualidade, sendo historicamente construídos e compartilhados entre os indivíduos (Borrillo, 2010; Lacerda, Pereira, \& Camino, 2002). Neste sentido, o presente estudo investiga o papel das representações sobre a natureza da homossexualidade na expressão do preconceito contra os homossexuais no ambiente de trabalho. Levantamos a hipótese de que essas crenças estão na base da expressão de atitudes e comportamentos preconceituosos nesse ambiente. 


\section{Crenças sobre a Natureza da Homossexualidade}

Krüger (1995) define crenças como proposições que, na sua formulação mais simples, afirmam ou negam uma relação entre dois aspectos concretos ou abstratos ou entre um objeto e um possível atributo desse objeto. Desta forma, as crenças podem ser estritamente pessoais, quando expressam, por exemplo, uma avaliação ou julgamento a respeito de alguém, mas também podem ser compartilhadas, como nos casos da opinião pública e dos estereótipos sociais. Neste estudo, focamos principalmente nas crenças socialmente compartilhadas sobre a homossexualidade. Estas crenças são, em grande parte, assentes em essencialismos psicológicos (Medin \& Ortony, 1989), ou seja, em características ou propriedades que são vistas como essenciais e que definem a natureza de um objeto ou grupo social (Allport, 1954). Desta forma, as pessoas tratam as categorias sociais não como artefatos produzidos socialmente, mas sim como categorias naturais, biologicamente determinadas (Rothbart \& Taylor, 1992).

O essencialismo psicológico pode ser considerado um viés cognitivo no processo de categorização social, que leva a uma crença de que cada categoria de objetos tem um conjunto fixo de atributos que definem a sua natureza (Medin \& Ortony, 1989; Rhodes, Leslie, \& Tworek, 2012). De acordo com essa perspectiva, a crença em essências subjacentes às categorias decorre da ideia de que essas essências mantêm uma relação com certas características biológicas genética, inata ou hormonal - que define todos os exemplares de uma categoria (Pereira, 2009). Rothbart e Taylor (1992) propuseram que, da mesma forma que as pessoas atribuem essências na descrição que fazem das categorias de objetos percebidos como naturais, elas também fazem isso para categorias sociais. Quando as pessoas fazem uso dessa crença para descrever a natureza dos grupos sociais é, sobretudo, para fundamentar as desigualdades sociais e a discriminação contra grupos minoritários (Pereira, Vala, \& Costa-Lopes, 2010; Vala, Pereira, Lima, $\&$ Leyens, 2012).
Hegarty e Pratto (2001) identificaram duas dimensões das crenças essencialistas sobre a homossexualidade: uma dimensão da imutabilidade, que é a crença de que a homossexualidade tem uma base biológica, fixada na infância e difícil de mudar; e uma dimensão de fundamentalismo, caracterizada pela crença de que a homossexualidade é uma categoria bem definida de indivíduos com características que fazem com que sejam necessariamente homossexuais e diferentes dos heterossexuais. Posteriormente, Haslam e Levy (2006) sugerem uma terceira dimensão, o universalismo, definida como a crença de que a homossexualidade é histórica e culturalmente variável. Estes autores constataram que as crenças na imutabilidade e na universalidade se correlacionam negativamente com o preconceito contra os homossexuais, porém a crença no fundamentalismo correlacionava-se positivamente (ver Pereira, 2009 para uma revisão).

A análise dessas dimensões essencialistas tem mostrado que esses atributos descrevem principalmente a crença numa natureza biológica dos grupos sociais, o que pode sugerir que as pessoas percebem esses grupos mais como categorias naturais do que como construções sociais (Rothbart \& Taylor, 1992). A investigação realizada nesse domínio tem restringido o seu escopo ao papel do essencialismo biológico, dando pouca ou nenhuma atenção a um conjunto mais amplo de crenças que pode ser mais relevante para fundamentar a discriminação contra os homossexuais, como a crença de que os grupos sociais podem ter origem divina, como produtos de disfunções psicológicas, entre outras (Pereira, 2009; Pereira, Torres, Falcão, \& Pereira, 2013). De fato, algumas concepções sobre a natureza da homossexualidade têm proposto que as teorias científicas (tanto biológicas como psicológicas) e religiosas sobre este tema têm contribuído significativamente para a estigmatização dos homossexuais, servindo de justificação para a adoção de comportamentos discriminatórios (Pereira, Pereira, \& Monteiro, 2016; Pereira, Torres, Pereira, \& Falcão, 2011).

Uma análise mais aprofundada sobre a importância das crenças sobre a natureza da homossexualidade deve considerar o essencialis- 
mo no âmbito dos processos descritos por Doise (1986) e por Moscovici (1976) na caracterização que fazem das teorias de senso comum sobre a realidade social (Moscovici \& Hewstone, 1983). A essencialização é um exemplo prototípico do que Moscovici descreveu como objetivação, explicando como as pessoas naturalizam conceitos e relações científicas, transformando-as em conhecimento de senso comum. Seguindo essas ideias, propõe-se que as crenças essencialistas sobre a homossexualidade são mais bem compreendidas quando analisadas como representações sociais ou teorias do senso comum sobre a natureza dos grupos sociais (Pereira et al., 2011). O processo psicossocial subjacente a essa concepção baseia-se na hipótese de que as teorias e práticas científicas, quando transformadas em conhecimentos de senso comum sobre a homossexualidade, servem de fundamentação para a adoção de comportamentos discriminatórios contra os homossexuais (Camino, 1998; Camino \& Pereira, 2000; Pereira et al., 2016).

Nesta perspectiva, Lacerda et al. (2002) identificaram cinco princípios organizadores das crenças sobre a homossexualidade, a saber: as crenças religiosas, baseadas na ideia de que a homossexualidade é uma profunda e imutável predisposição para o pecado e para a desobediência ao que se julga serem as leis de Deus; as crenças ético-morais, assentes na ideia de que a natureza da homossexualidade é caracterizada pela tendência das pessoas para violarem valores morais, incluindo o que se acredita ser o valor da decência, da moralidade e das boas maneiras; as crenças psicológicas, alimentadas por modelos científicos propondo que a homossexualidade tem base psicológica e afetiva, relacionada com alguma situação traumática vivida na infância; as crenças biológicas, também fundamentadas em modelos que proclamam que os homossexuais têm uma essência de natureza genética, que é transmitida hereditariamente e que se manifesta em disfunções hormonais ou em qualquer cariz biológico em geral; e por fim as crenças psicossociais, que são um conjunto de crenças não-essencialistas assentes na ideia de que a homossexualidade tem base cultural e representa uma expressão normal da sexualidade humana.
Lacerda et al. (2002) também constataram que o preconceito flagrante em relação aos homossexuais baseava-se na crença em uma suposta natureza ético-moral e religiosa da homossexualidade, enquanto que o preconceito sutil se relacionava com crenças na natureza biológica e psicológica. Apenas as crenças psicossociais sobre a homossexualidade estavam relacionadas com atitudes igualitárias face aos heterossexuais. Por conseguinte, concluíram que as representações sociais sobre a natureza da homossexualidade podem cooperar para a manutenção de práticas sociais homofóbicas pelo fato dessas crenças serem bastante irradiadas no pensamento de senso comum e serem utilizadas para legitimar as políticas e ações sociais que são orientadas para os homossexuais (Lacerda et al., 2002).

As crenças acerca da natureza da homossexualidade podem contribuir para a manutenção de uma imagem fixa e imutável dos homossexuais, na medida em que salientam uma representação essencialista do homossexual como portador de alguma anormalidade biológica ou psicológica, ou uma representação do homossexual como portador de uma essência, ainda que difusa, que o impulsiona para a violação dos valores tradicionais que sustentam o status quo. Ademais, Pereira et al. (2016) demonstram que diferenças individuais em termos de crenças religiosas e biológicas sobre a natureza da homossexualidade anulam o efeito da norma antipreconceito. Esses autores argumentam que quanto mais as pessoas representam a homossexualidade com base nas crenças religiosas e biológicas, mais resistentes se sentirão em relação à pressão exercida pela norma antipreconceito, uma vez que terão fundamentos fortes para manterem inalteradas as suas atitudes em relação aos homossexuais.

\section{O Preconceito contra Homossexuais no Ambiente de Trabalho}

De acordo com Marco, Hoel, Arenas e Munduate (2015), a discriminação baseada na orientação sexual é bastante comum no ambiente de trabalho. Embora as expressões abertas de discriminação, tais como hostilidade, violência física e psicológica, que violam abertamente as normas sociais, tenham diminuído, formas mais sutis e 
ambíguas têm se mantido (Cortina, Kabat-Farr, Leskinen, Huerta, \& Magley, 2013; Einarsdóttir, Hoel, \& Lewis, 2015). Marco et al. (2015) apontam que o preconceito contra homossexuais se revela através de piadas, linguagem depreciativa, estereótipos negativos e comportamento intrusivos. Irigaray, Saraiva e Carrieri (2010), ao estudarem o uso de expressões emocionais como instrumento de discriminação dos homossexuais no ambiente de trabalho, concluíram que o humor - por meio de ironia, piadas e anedotas naturaliza a homofobia e que este é usado como um sutil instrumento de controle da sexualidade. Segundo Garcia e Souza (2010), o preconceito contra os homossexuais também é identificado no acesso às vagas de trabalho, quando se nega a possibilidade de contratação a homossexuais declarados, ou no tratamento, quando os homossexuais recebem poucas recompensas ou oportunidades de crescimento no trabalho devido a sua orientação sexual.

Nas empresas, os comportamentos preconceituosos e discriminatórios podem infligir danos pessoais e profissionais, tais como: a possível perda de emprego em virtude da orientação sexual; a menor probabilidade de obtenção de promoções e ascensão na carreira profissional (Einarsdóttir et al., 2015). Ademais, as avaliações do desempenho são fortemente influenciadas quando o alvo da avaliação é um homossexual (Siqueira \& Zauli-Fellows, 2006). Perante esse panorama, os indivíduos homossexuais tendem a camuflar a sua orientação sexual, na tentativa de evitar discriminação e superar as dificuldades para a progressão da sua carreira profissional.

Badgett (1997), considerando e analisando várias pesquisas efetuadas nos Estados Unidos com os dados do General Social Survey e do Yankelovich Monitor, verificou que o homossexual, quando comparado ao heterossexual com a mesma experiência, educação, profissão, estado civil e região de residência, recebe remuneração inferior, em média de $11 \%$ a $27 \%$. Como também relatam Mays e Cochran (2001), a probabilidade de ser alvo de agressões físicas ou verbais e até mesmo de ser demitido, é duas vezes maior no caso dos homossexuais (Siqueira \& Zauli-Fellows, 2006). Esta informação reforça a ideia de Siqueira Saraiva, Carrieri, Lima e Andrade, (2009), segundo a qual a homofobia é um problema presente no ambiente de trabalho.

De acordo com Ragins e Cornwell (2001), embora a existência de uma legislação que proíba a discriminação sexual no trabalho seja importante na redução da discriminação, o fator mais relevante para a diminuição da discriminação não é a lei, mas a existência de uma cultura organizacional "amigável" em relação aos homossexuais. Em virtude disso, a luta contra a discriminação, o preconceito e a violência dirigida contra homossexuais vem ganhando destaque, encabeçada principalmente por grupos de defesa dos direitos dos homossexuais. No entanto, o que se percebe é que as diretrizes de igualdade e proteção aos homossexuais constituem mais a exceção do que a regra, mesmo diante das práticas que buscam agregar diversidade na força de trabalho das organizações (Ferreira, 2007).

Diante da evidência de discriminação e preconceito contra homossexuais no ambiente de trabalho, o estudo que se apresenta tem por objetivo analisar o papel das representações sobre a natureza da homossexualidade na expressão do preconceito contra os homossexuais no ambiente de trabalho. Embora se tenha bem documentado na literatura em psicologia organizacional e em administração as consequências práticas do preconceito contra os homossexuais no ambiente de trabalho, que reflete negativamente nas suas carreiras e também para o desempenho da organização, são escassos os estudos a nível organizacional que buscam compreender os possíveis fatores individuais que contribuem para este fenômeno. É possível que um destes fatores individuais sejam as crenças acerca da natureza da homossexualidade que, como dito anteriormente, são conhecimentos de senso comum sobre a homossexualidade que servem de fundamentação para a adoção de comportamentos discriminatórios contra homossexuais (Camino, 1998).

\section{Método}

O presente estudo analisa especificamente o papel de crenças sobre a natureza da homossexualidade no preconceito contra os homossexuais, 
sendo o preconceito abordado em duas de suas principais dimensões: a rejeição à proximidade $\mathrm{e}$ a expressão emocional (positiva ou negativa). A hipótese a ser testada no presente estudo é a de que haverá uma relação positiva entre as crenças ético-morais e religiosas e o preconceito, ou seja, quanto maior a adesão a estas crenças maior será a rejeição à proximidade com homossexuais, menor serão as expressões de emoções positivas e, em oposição, maior serão as emoções negativas em relação aos homossexuais. $\mathrm{O}$ padrão oposto deve emergir entre a crença na natureza cultural da homossexualidade e o preconceito, em que a maior adesão a este tipo de crença deve estar associada a menor rejeição à proximidade, menos emoções negativas e mais expressão de emoções positivas. Essas hipóteses têm por base estudos prévios que têm indicado que o apoio a políticas discriminatórias contra os homossexuais está relacionado positivamente com as crenças religiosas e ético-morais e negativamente com as crenças em fatores culturais (Pereira, Alfaia, Souza, \& Lima, 2014; Pereira et al., 2016; Pereira et al., 2013; Pereira et al., 2011). Por último, considerando que as atitudes em relação aos homossexuais são consistentemente relacionadas com as características demográficas dos indivíduos (Haslam \& Levy, 2006; Wilkinson \& Roys, 2005), as hipóteses foram testadas controlando-se o efeito dessas variáveis (Pereira et al., 2013).

\section{Participantes}

Participaram deste estudo 169 trabalhadores que se autoidentificaram como heterossexuais. A amostra foi selecionada por um procedimento não probabilístico de amostragem por conveniência. A coleta de dados foi realizada em cinco empresas portuguesas de grande porte, sendo uma do setor do comércio mobiliário, uma de telecomunicações e as outras três de gestão internacional. A idade dos participantes variou entre 21 e 55 anos $(M=32,80, D P=8,29)$. A maioria dos participantes é do sexo feminino $(68 \%)$, solteira $(57 \%)$ e com escolaridade superior $(83,4 \%)$. A maior percentagem de inquiridos $(22,5 \%)$ estavam trabalhando na empresa há mais de um ano.

\section{Instrumentos}

Foi aplicado um questionário contendo as seguintes escalas:

Escala de Crenças sobre a Natureza da Homossexualidade. Esta escala foi elaborada por Lacerda et al. (2002) e adaptada para Portugal por Pereira, Monteiro e Camino (2009). É composta por 15 itens que medem cinco tipos de crenças sobre a natureza da homossexualidade, a saber: religiosas (e.g., As causas da homossexualidade estão relacionadas com a falta de obediência à Palavra de Deus), biológicas (e.g., As causas da homossexualidade estão relacionadas com disfunções hormonais), ético-morais (e.g., As causas da homossexualidade estão relacionadas com a falta de caráter), psicológicas (e.g., As causas da homossexualidade estão relacionadas com abusos sexuais sofridos na infância) e culturais (e.g., A causa da homossexualidade está relacionada com as práticas culturais de cada sociedade). Foi utilizada uma escala de sete pontos, variando entre 1 (discordo totalmente) e 7 (concordo totalmente). Uma análise fatorial (método dos eixos principais) fixando a extração de cinco fatores mostra que estes explicaram 78,5\% da variância. Os Alfas de Cronbach para os cinco tipos de crenças foram os seguintes: religiosas $(\alpha=0,89)$; ético-morais $(\alpha=0,88)$; psicológicas $(\alpha=0,79)$; culturais $(\alpha=0,49)$; e biológicas $(\alpha$ $=0,78)$.

Medida de Preconceito. Para medir o preconceito foi empregada uma versão adaptada (Lacerda et al., 2002) da Escala de Rejeição à Intimidade de Pettigrew e Meertens (1995). No presente estudo, a escala de rejeição a relações de proximidade com homossexuais foi adaptada para o contexto do trabalho, sendo os participantes instruídos a indicarem em que medida se sentiriam constrangidos perante situações específicas nas relações laborais. O questionário contemplava 12 itens e a tarefa dos participantes era indicar o seu grau de constrangimento em relação a cada uma das situações usando uma escala de sete pontos, variando entre 1 (nada constrangido) e 7 (muitíssimo constrangido). São exemplos de itens: "Ter na sua empresa uma pessoa homossexual", "Ter na equipa de trabalho um (a) colega homossexual", "Ter um chefe homos- 
sexual". Uma análise fatorial exploratória (método dos eixos principais), indicou a extração de um fator (cargas fatoriais variaram de $0,70 \mathrm{a}$ 0,96), que explicou $79,7 \%$ da variabilidade nas respostas. A medida apresenta consistência interna elevada $(\alpha=0,97)$, o que permite a construção de um índice de preconceito onde os escores mais elevados indicam maior preconceito contra homossexuais.

Escala de Expressão Emocional. Originalmente proposta por Dijker (1987), esta escala foi adaptada para Portugal por Pereira et al. (2009). É composta por uma lista de 10 emoções, sendo 5 positivas (aceitação, satisfação, admiração, respeito e amor) e 5 negativas (desprezo, raiva, tristeza, pena e nojo), onde os participantes indicam, numa escala variando entre 1 (nunca) e 5 (muito frequentemente), a frequência com que sentem cada emoção em relação a homossexuais. Os escores obtidos foram submetidos a uma análise fatorial exploratória (método dos eixos principais), sendo extraídos dois fatores. O primeiro, denominado emoções positivas, explicou $40,6 \%$ da variância, com cargas fatoriais variando entre 0,64 e 0,85 , seu índice de consistência interna foi de 0,83 . O segundo fator, denominado emoções negativas, explicou $19,8 \%$ da variância, apresentou cargas fatoriais variando entre 0,64 e 0,78 com índice de consistência interna de 0,79 .

\section{Procedimentos de Coleta de Dados}

Inicialmente entrou-se em contato com as empresas para solicitar o acesso aos funcionários para a realização de uma pesquisa sobre o preconceito contra homossexuais no ambiente de trabalho. Com a autorização das empresas, pesquisadores devidamente treinados abordavam os trabalhadores durante seu tempo livre, convidando-os a colaborar num estudo sobre comportamentos sociais. O critério para inclusão na amostra final era o participante estar disposto a colaborar com o estudo e ser heterossexual (avaliado através de um item no questionário, no qual o participante indicava sua orientação sexual). A coleta de dados se deu através de questionários, em formato papel/lápis, respondidos no ambiente de trabalho, e durou em média 15 minutos.

\section{Procedimentos de Análise de Dados}

A análise dos dados seguiu as indicações propostas no Modelo da Análise Quantitativa das Representações Sociais (Doise, Clémence, \& Lorenzi-Cioldi, 1993), especialmente pelo uso de modelos de regressão para analisar como essas representações contribuem para o posicionamento das pessoas em relação aos temas socialmente relevantes, como o preconceito e a discriminação. Assim, para responder ao problema de investigação levantado, foram realizadas análises de regressão com o intuito de conhecer em que medida as crenças sobre a natureza da homossexualidade estão relacionadas com os indicadores de homofobia nas organizações (rejeição à proximidade, expressão de emoções positivas e negativas). Foram realizadas três análises de regressão múltipla, hierárquica, com método Enter, para as variáveis-critério rejeição à proximidade, emoções negativas e emoções positivas. Foram calculadas duas regressões por bloco de variáveis para cada variável-critério. Na primeira equação incluiu-se o bloco das variáveis sociodemográficas (sexo, idade, antiguidade na empresa, nível de escolaridade e identificação com a empresa). Na segunda equação acrescentou-se o bloco das crenças sobre a homossexualidade (religiosas, ético-morais, biológicas, psicológicas e culturais).

\section{Procedimentos Éticos}

Os participantes foram informados de que a participação na pesquisa era voluntária e que as informações coletadas seriam tratadas de forma confidencial, sendo utilizadas apenas para fins acadêmicos, mantendo-se assim o anonimato dos participantes. Todas as pesquisas e procedimentos propostos neste projeto obedeceram às determinações éticas e normativas que regem a pesquisa com seres humanos, de acordo com o preconizado pela Declaração de Helsinque de 2013. 


\section{Resultados}

A primeira análise de regressão teve a rejeição à proximidade como variável-critério, sendo o coeficiente de regressão múltipla obtido com a primeira equação (variáveis sociodemográficas) significativamente diferente de zero, $R=0,34, F(5,163)=4,30, p<0,001$. Como se pode constatar na Tabela 1, o sexo prediz significativamente a rejeição à proximidade, sendo que os participantes do sexo masculino expressam mais rejeição à proximidade do que as mulheres. $\mathrm{Na}$ segunda equação, o coeficiente de regressão múltipla também é diferente de zero, $R=0,70$, $F(10,158)=15,40, p<0,001$. A variável sexo continua predizendo significativamente a rejeição à proximidade. O efeito das crenças ético-morais é significativo e o efeito das crenças biológicas é apenas marginalmente significativo $(t=1,79, p=0,075)$. Deste modo, a maior adesão a crenças ético-morais implica maior rejeição à proximidade. De forma similar, uma maior adesão às crenças biológicas está associada a uma maior rejeição à proximidade. Além disso, a inclusão das crenças apresenta um incremento significativo na explicação da variância da rejeição à proximidade, $F_{\text {Change }}(5,158)=23,5, p<$ 0,001 . Portanto, as crenças sobre a natureza da homossexualidade predizem significativamente a rejeição à proximidade, mesmo controlando os efeitos das variáveis sociodemográficas.

Tabela 1

Pesos de Regressão Padronizados ( $\beta$ ) dos Preditores do Preconceito

\begin{tabular}{ccccccc}
\hline & \multicolumn{7}{c}{ Preconceito } \\
\cline { 2 - 7 } Preditores & \multicolumn{2}{c}{$\begin{array}{c}\text { Rejeição } \\
\text { Proximidade }\end{array}$} & \multicolumn{2}{c}{$\begin{array}{c}\text { Emoções } \\
\text { Positivas }\end{array}$} & \multicolumn{2}{c}{$\begin{array}{c}\text { Emoções } \\
\text { Negativas }\end{array}$} \\
\hline Sexo & $-0,32^{* * *}$ & $-0,24^{* * *}$ & $0,37^{* * *}$ & $0,31^{* * *}$ & $-0,21^{* *}$ & $-0,14^{*}$ \\
Idade & 0,17 & 0,10 & $-0,08$ & $-0,03$ & $-0,05$ & $-0,12$ \\
Antiguidade na empresa & $-0,15$ & $-0,12$ & $-0,15$ & $-0,17$ & 0,03 & 0,06 \\
Nível de escolaridade & 0,01 & 0,11 & $-0,14 \dagger$ & $-0,13^{*}$ & $-0,06$ & $-0,06$ \\
Identificação com a empresa & 0,07 & $-0,02$ & $-0,10$ & $-0,05$ & 0,09 & 0,01 \\
Religiosas & & 0,06 & & 0,02 & & 0,13 \\
Ético-Morais & & $0,43^{* *}$ & & $-0,27$ & & $0,41^{*}$ \\
Biológicas & & $0,16 \dagger$ & & $-0,08$ & & 0,12 \\
Psicológicas & & 0,02 & & $-0,12$ & & $-0,05$ \\
Culturais & & 0,01 & & $-0,04$ & & 0,02 \\
$R_{\text {Ajustado }}^{2}$ & 0,09 & 0,46 & 0,17 & 0,33 & 0,02 & 0,34 \\
\hline
\end{tabular}

Nota. Para o sexo foram atribuídos os seguintes valores: $0=$ masculino e $1=$ feminino. $\dagger p<0,08, * p<0,05, * * p<0,01, * * * p<0,001$.

Em uma segunda análise, regrediu-se as emoções positivas no modelo onde apenas variáveis sociodemográficas foram incluídas como preditoras, obtendo-se um coeficiente de regressão significativo, $R=0,44, F(5,163)=7,68$, $p<0,001$. O sexo prediz significativamente a expressão de emoções positivas, sendo que as mulheres tendem a expressá-las mais que os homens. Na segunda regressão, quando as crenças são consideradas no modelo, o coeficiente de regressão continua significativo, $R=0,61$, $F(10,158)=9,18, p<0,001$. O efeito da variável sexo foi significativo, como também o nível de escolaridade. Estes resultados indicam que as mulheres expressam mais emoções positivas do que os homens e que quanto maior o nível de 
escolaridade menor é a expressão de emoções positivas em relação aos homossexuais. Ademais, a segunda regressão apresenta um incremento significativo na explicação na explicação das emoções positivas, $F_{\text {Change }}(5,158)=8,83, p$ $<0,001$, embora o efeito das crenças não tenha sido significativo.

Por último, na terceira regressão múltipla, com as emoções negativas como critério, a primeira equação não tem um coeficiente significativo, $R=0,23, F(5,163)=1,84, p=0,108$. Na segunda equação, incluindo as crenças sobre a homossexualidade, o coeficiente de regressão é diferente de zero, $R=0,61, F(10,158)=9,56$, $p<0,001$. Novamente, o efeito do sexo é significativo, os homens expressam mais emoções negativas do que as mulheres. $\mathrm{O}$ efeito das crenças ético-morais também foi significativo, sendo que maior adesão a essas crenças implica maior expressão de emoções negativas. Além disso, a inclusão das crenças apresenta um incremento significativo na explicação da expressão de emoções negativas, $F_{\text {Change }}(5,158)=16,41, p<$ 0,001 .

\section{Discussão}

O presente estudo teve por objetivo analisar o papel das crenças sobre a homossexualidade no preconceito contra homossexuais no ambiente de trabalho, mais especificamente na rejeição à proximidade e na expressão de emoções positivas e negativas. Os resultados obtidos confirmaram parcialmente as hipóteses levantadas. Como proposto, as crenças sobre a homossexualidade baseadas em conceitos ético-morais (a crença de que os homossexuais partilham uma tendência para o violar os valores tradicionais da decência, da moralidade e das boas maneiras) predizem a rejeição à proximidade com homossexuais e a maior expressão de emoções negativas. Este resultado é mais uma evidência empírica a reforçar o papel desempenhado por esta crença como forte preditor do preconceito contra homossexuais em contextos diversos, tais como o universitário, religioso e no futebol (Lacerda et al., 2002; Pereira et al., 2014; Pereira et al., 2013; Pereira et al., 2011).
Por sua vez, as crenças religiosas não predisseram o preconceito contra os homossexuais. Uma possível explicação para esse resultado encontra-se no fato de muitos respondentes terem relatado que não tem ou não acreditam em religião $(31,4 \%)$. Ademais, entre os que indicaram ter uma religião, é predominante o número de católicos $(70 \%)$ que, como observado por Pereira et al. (2011), em um outro estudo sobre a natureza da homossexualidade, tendem acreditar em menor grau na natureza religiosa da homossexualidade quando comparados com aqueles de religião evangélica. No entanto, nesse estudo não avaliamos diferenças entre católicos e evangélicos. A crença biológica apresentou um peso de regressão marginalmente significativo com a rejeição à proximidade, indicando uma tendência de maior rejeição à proximidade consoante as pessoas endossam em maior medida essa crença. Por outro lado, a crença na natureza cultural da homossexualidade não prediz um menor preconceito contra homossexuais, não corroborando o que foi hipotetizado. Por fim, quanto às variáveis sociodemográficas, vale ressaltar que o sexo do respondente apresentou um padrão de predição consoante com o esperado, sendo que os homens tendem a apresentar em maior grau rejeição à proximidade e maior expressão de emoções negativas do que as mulheres, que expressam mais emoções positivas do que os homens.

A relação entre as crenças na natureza ético-moral da homossexualidade e o preconceito vêm confirmar os resultados de investigações anteriores, mostrando que estas crenças estão na base de atitudes antigays (Lacerda et al., 2002; Pereira et al., 2013). As pessoas que acreditam em uma causa ética-moral expressam maior rejeição às relações de proximidade e sentem mais emoções negativas e menos emoções positivas em relação aos homossexuais, apresentando uma expressão mais flagrante do preconceito (Pettigrew \& Meertens, 1995). Este grupo poderia ser descrito como aqueles que utilizam o discurso de que se sentem mal ou pouco a vontade em relação a trabalhar e conviver com homossexuais e não concordam com a prática de relações sexuais com pessoas do mesmo sexo, 
associando-a à falta de caráter, de respeito e de valores morais (Pereira, 2009; Pereira et al., 2013).

Quanto ao papel das variáveis sociodemográficas, apenas o sexo prediz significativamente os três tipos de expressão do preconceito aqui analisadas. Tais resultados vêm a corroborar as pesquisas que indicam que as mulheres apresentam níveis de preconceitos inferiores aos dos homens (Brandyberry \& Macnair, 1996; Hogan \& Rentz, 1996; Lacerda et al., 2002). No estudo de Pereira et al. (2009) sobre normas sociais e preconceito contra homossexuais, é relevante o efeito do sexo, em que as mulheres apresentam menor nível de preconceito contra homossexuais. Este efeito pode ser explicado com base na hipótese de que homens e mulheres têm crenças diferentes sobre o papel de gênero (Whitley, 2001) e ainda no fato das mulheres terem maior motivação interna para responder sem preconceito do que os homens (Ratcliff, Lassiter, Markman, \& Snyder, 2006).

Os resultados mostraram que o nível de escolaridade está negativamente associado à expressão de emoções positivas, ou seja, quanto maior o nível de escolaridade menor será a expressão de emoções positivas em relação aos homossexuais. Embora os respondentes não exprimam emoções negativas, a baixa expressão de emoções positivas pode estar associada ao preconceito sutil, onde o respondente sente menos emoções positivas para com os grupos externos ao seu (Pettigrew \& Meertens, 1995).

Em síntese, os resultados apresentados sustentam empiricamente a ideia de que as crenças que os indivíduos têm sobre a natureza da homossexualidade estão na base do preconceito contra os homossexuais (Lacerda et al., 2002). $\mathrm{O}$ estudo demonstrou que as crenças sobre a natureza da homossexualidade, especificamente as ético-morais, podem ser um fator motivador de tensões intergrupais no contexto laboral. Deste modo, é necessário criar estratégias que tenham como objetivo principal a prevenção ou a redução do preconceito nas relações laborais. Uma forma útil seria propor seminários sobre a importância e respeito à diversidade, promovendo esclarecimentos sobre aspectos específicos da sexualidade humana com o intuito de dirimir crenças assentes em essencialismos, preconceitos e teorias não científicas. Lucas e Kaplan (1994) recordam que as empresas não podem impor as crenças aos seus empregados, mas podem tentar ensinar um comportamento que seja distante de qualquer discriminação e adequado ao ambiente de trabalho.

Será vantajoso não só para os trabalhadores, mas principalmente para a organização promover o bem-estar organizacional e uma boa relação entre colaboradores, o que pode contribuir para incrementar a produtividade e o sucesso organizacional. É necessário prover um ambiente que gere contato intergrupal integrado e positivamente valorizado de modo a facilitar relações harmoniosas, o que pode leva a uma maior performance na medida em que as organizações precisam de "gerenciar a diversidade" para assim saírem mais fortalecidas (Siqueira \& Zauli-Fellows, 2006).

Embora a investigação efetuada ofereça evidências empíricas suficientemente fortes para a sustentação de parte das hipóteses aqui levantadas, o estudo realizado não está isento de limitações. Primeiramente, os resultados que foram encontrados não devem ser vistos como tendências gerais ocorridas nas empresas, uma vez que este estudo tem uma amostra de trabalhadores de zonas específicas, não sendo esta representativa da população trabalhadora em Portugal. Ademais, variáveis macro-organizacionais, a exemplo da cultura organizacional das empresas, não foram aqui avaliadas. Em função da importância das variáveis macro-organizacionais para o comportamento individual, estudos futuros poderão avaliar, por exemplo, se a cultura organizacional é uma variável moderadora entre os fatores individuais e a expressão do preconceito. Outra limitação remete-se ao fato da natureza correlacional do estudo, o que não permite que se infira a presença de relações de causalidade entre as variáveis. Por fim, grande parte das crenças empregadas apresentaram valência negativa, isto se deve provavelmente à construção sociohistórica dessas crenças que, em geral, entendem a homossexualidade como uma parte desviante e negativa da sexualidade humana (Freud, 1905/1962; Gre- 
enberg \& Bystryn, 1982). Assim, estudos futuros poderão adotar uma definição mais inclusiva, abarcando aspectos positivos acerca da natureza da homossexualidade que não foram tidos em conta neste trabalho. Estudos futuros poderão ainda analisar em que medida os resultados aqui obtidos estariam relacionados com uma variável comportamental, como, por exemplo, a oposição a contratação de homossexuais, buscando entender como estes conceitos - crenças, preconceito e discriminação - relacionam-se no âmbito organizacional.

\section{Considerações Finais}

Este estudo demonstrou que as crenças sobre a natureza da homossexualidade, como representações sociais, analisadas no contexto das relações intergrupais em ambiente de trabalho, podem explicar o preconceito contra os homossexuais nesse ambiente. Desta forma, o papel das teorias do senso comum sobre a natureza da homossexualidade deve ser tido em conta no desenvolvimento e aplicação de políticas públicas com o objetivo de reduzir o preconceito e promover a inclusão social dos homossexuais nos mais diversos contextos da sociedade. Essas políticas devem buscar descontruir as crenças relacionadas com o preconceito, a exemplo das crenças na natureza ético-moral, e reforçar aquelas relacionadas com uma maior aceitação e inclusão social, a exemplo das crenças na natureza cultural da homossexualidade.

\section{Referências}

Allport, G. W. (1954). The nature of prejudice. Reading, MA: Addison-Wesley.

Badgett, M. L. (1997). Vulnerability in the workplace: Evidence of anti-gay discrimination. Angles: The Policy Journal of the Institute for Gay and Lesbian Studies, 2, 1-4.

Borrillo, D. (2010). Homofobia: História e crítica de um preconceito. Belo Horizonte, MG: Autêntica.

Brandyberry, L. J., \& MacNair, R. R. (1996). The content and function of attitudes toward AIDS. Journal of College Student Development, 37, $335-346$
Camino, L. (1998). Direitos humanos e psicologia. In Comissão de Direitos Humanos do Conselho Federal de Psicologia (Ed.), Psicologia, ética e direitos humanos (pp. 39-63). Brasília: Conselho Federal de Psicologia.

Camino, L., \& Pereira, C. (2000). O papel da Psicologia na construção dos direitos humanos: Análise das teorias e práticas psicológicas na discriminação ao homossexualismo. Perfil, 13(13), 49-69.

Cortina, L. M., Kabat-Farr, D., Leskinen, E. A., Huerta, M., \& Magley, V. J. (2013). Selective incivility as modern discrimination in organizations: Evidence and impact. Journal of Management, 39, 1579-1605. doi:10.1177/0149206311418835

Dijker, A. J. M. (1987). Emotional reactions to ethnic minorities. European Journal of Social Psychology, 17, 305-325. doi:10.1002/ ejsp.2420170306

Doise, W. (1986). Les represésentations sociales: définition dun concept. In W. Doise \& A. Palmonari (Eds.), Létude des représentations socials (pp. 82-95). Paris: Delachaux.

Doise, W., Clémence, A., \& Lorenzi-Cioldi, F. (1993). The quantitative analysis of social representations. Hemel Hempstead, UK: Harvester Wheatsheaf.

Einarsdóttir, A., Hoel, H., \& Lewis, D. (2015). 'It's nothing personal': Anti-homosexuality in the British workplace. Sociology, 49, 1183-1199. doi: $10.1177 / 0038038515582160$

Eliason, M. J., Dejoseph, J., Dibble, S., Deevey, S., \& Chinn, P. (2011). Lesbian, gay, bisexual, transgender, and queer/questioning nurses' experiences in the workplace. Journal of Professional Nursing, 27, 237-244. doi:10.1016/j.profnurs.2011.03.003

Ferreira, R. C. (2007). O gay no ambiente de trabalho: Uma análise dos efeitos em ser gay nas organizações contemporâneas (Dissertação de mestrado em Administração de Empresas, Universidade de Brasília, DF, Brasil).

Freud, S. (1962). Three essays on the Theory of Sexuality Translation. In J. Strachey (Ed.), The standard edition of the complete psychological works of Sigmund Freud (Vol. 7, pp. 136-244). London: Hogarth. (Original work published 1905)

Garcia, A., \& Souza, E. M. (2010). Sexualidade e trabalho: Estudo sobre a discriminação de 
homossexuais masculinos no setor bancário. Revista de Administração Pública, 44, 13531357. doi:10.1590/S0034-76122010000600005

Greenberg, D. F., \& Bystryn, M. (1982). Christian intolerance of homosexuality. American Journal of Sociology, 88, 515-548. doi:10.1086/227706

Haslam, N., \& Levy, S. R. (2006). Essentialist beliefs about homosexuality: Structure and implications for prejudice. Personality and Social Psychology Bulletin, 32(4), 471-485. doi:10.1177/0146167205276516

Hegarty, P., \& Pratto, F. (2001). Sexual orientation beliefs: Their relationship to antigay attitudes and biological determinist arguments. Journal of Homosexuality, 41, 121-135. doi:10.1300/ J082v41n01_04

Hogan, T., \& Rentz, A. (1996). Homophobia in the academy. Journal of College Student Development, 37, 309-314. doi:10.1037/sgd0000136

Irigaray, H. A. R., Saraiva, L. A. S., \& Carrieri, A. (2010). Humor e discriminação por orientação sexual no ambiente organizacional. Revista de Administração Contemporânea, 14, 890-906. doi:10.1590/S1415-65552010000500008

Krüger, H. (1995). Psicologia das Crenças: Perspectivas teóricas (Tese do concurso público para professor titular de Psicologia Social, Instituto de Psicologia da Universidade do Estado do Rio de Janeiro, RJ, Brasil).

Lacerda, M., Pereira, C., \& Camino, L. (2002). Um estudo sobre as formas de preconceito contra homossexuais na perspectiva das representações sociais. Psicologia: Reflexão e Crítica, 15, 165 178. doi:10.1590/S0102-79722002000100018

Lucas, J. H., \& Kaplan, M. G. (1994). Unlocking the corporate closet. Training and Development, 48 , 34-38.

Marco, D., Hoel, H., Arenas, A., \& Munduate, L. (2015). Workplace incivility as modern sexual prejudice. Journal of Interpersonal Violence, 23, 1-27. doi:10.1177/0886260515621083

Mays, V. M., \& Cochran, S. D. (2001). Mental health correlates of perceived discrimination among lesbian, gay, and bisexual adults in the United States. American Journal of Public Health, 91, 1869-1876. doi:10.2105/AJPH.91.11.1869

Medin, D., \& Ortony, A. (1989). Psychological Essentialism. In S. Vosniadou \& A. Ortony (Eds.),
Similarity and analogical reasoning. New York: Cambridge Academic Press.

Mizzi, R. C. (2013). “There aren't any gays here": Encountering heteroprofessionalism in an international development workplace. Journal of Homosexuality, 60, 1602-1624. doi:10.1080/00 918369.2013 .824341

Moscovici, S. (1976). La psychanalyse, son image et son public. Paris: Presses Universitaires de France.

Moscovici, S., \& Hewstone, M. (1983). Social representations and social explanations: From the "naive" to the "amateur" scientist. In M. Hewstone (Ed.), Attribution Theory: Social and functional extensions (pp. 98-125). Oxford, UK: Blackwell.

Pereira, A. S. (2009). Normas sociais, crenças sobre a natureza da homossexualidade e preconceito contra os homossexuais (Tese de doutorado em Psicologia Social e Organizacional, ISCTE Instituto Universitário de Lisboa, Portugal).

Pereira, A. S., Alfaia, A. J. B., Souza, L. E. C., \& Lima, T. J. S. (2014). Preconceito contra homossexuais no contexto do futebol. Psicologia \& Sociedade, 26, 737-745. doi:10.1590/S010271822014000300022

Pereira, A. S., Monteiro, M. B., \& Camino, L. (2009). Estudo da validação das escalas de crenças sobre a natureza da homossexualidade e de preconceito contra homossexuais. Laboratório de Psicologia, 7, 21-32. doi:10.14417/lp.683

Pereira, A. S., Pereira, C. R., \& Monteiro, M. B. (2016). Normative pressure to reduce prejudice against homossexuals: The buffering role of beliefs about the nature of homosexuality. Personality and Individual Differences, 96, 8899. doi:10.1016/j.paid.2016.02.042

Pereira, C., Torres, A. R., Falcão, L., \& Pereira, A. (2013). O papel de representações sociais sobre a natureza da homossexualidade na oposição ao casamento civil e à adoção por famílias homoafetivas. Psicologia: Teoria e Pesquisa, 29, 7989. doi:10.1590/S0102-37722013000100010

Pereira, C., Torres, A. R., Pereira, A., \& Falcão, L. (2011). Preconceito contra homossexuais e representações sociais da homossexualidade em seminaristas e evangélicos. Psicologia: Teoria e Pesquisa, 27, 77-82. doi:10.1590/S010237722011000100010 
Pereira, C., Vala, J., \& Costa-Lopes, R. (2010). From prejudice to discrimination: The legitimizing role of perceived threat in discrimination against immigrants. European Journal of Social Psychology, 40, 1231-1250. doi:10.1002/ ejsp.718

Pettigrew, T. F., \& Meertens, R. W. (1995). Subtle and blatant prejudice in Western Europe. European Journal of Social Psychology, 25, 57-75. doi:10.1002/ejsp.2420250106

Ragins, B. R., \& Cornwell, J. M. (2001). Pink triangles: Antecedents and consequences of perceived workplace discrimination against gay and lesbian employees. Journal of Applied Psychology, 86, 1244-1261. doi:10.1037/00219010.86.6.1244

Ratcliff, J. J., Lassiter, G. D., Markman, K. D., \& Snyder, C. J. (2006). Gender differences in attitudes toward gay men and lesbians: The role of motivation to respond without prejudice. Personality and Social Psychology Bulletin, 33, 1325-1338. doi:10.1177/0146167206290213

Rhodes, M., Leslie, S. J., \& Tworek, C. M. (2012). Cultural transmission of social essentialism. Procedings of the National Academy of Science, 109, 13526-13531. doi:10.1073/ pnas. 1208951109

Rothbart, M., \& Taylor, M. (1992). Category labels and social reality: Do we view social categories as natural kinds? In G. Semin \& K. Fiedler (Eds.), Language, interaction and social cognition (pp. 11-36). Newbury Park, CA: Sage.

Siqueira, M. V. S., Saraiva, L. A. S., Carrieri, A. P., Lima, H. K. B., \& Andrade, A. J. A. (2009). Homofobia e violência moral no trabalho no Distrito Federal. Revista Organizações e Sociedades, $16,447-461$.
Siqueira, M. V. S., \& Zauli-Fellows, A. (2006). Diversidade e identidade gay nas organizações. Gestão.Org - Revista Eletrônica de Gestão Organizacional, 4, 69-81.

Vala, J., Pereira, C. R., Lima, M. E. O., \& Leyens, J. P. (2012). Intergroup time bias and racialized social relations. Personality and Social Psychology Bulletin, 38, 491-504. doi:10.1177/0146167211429746

Whitley, B. E. (2001). Gender-role variables and attitudes toward homosexuality. Sex Roles, 45, 692-721. doi: 10.1023/A:1015640318045

Wilkinson, W. W., \& Roys, A. C. (2005). The components of sexual orientation, religiosity, and heterosexuals' impressions of gay men and lesbians. The Journal of Social Psychology, 145, 65-83. doi: 10.3200/SOCP.145.1.65-84

Williams, C., \& Guiffre, P. (2011). From Organizational Sexuality to Queer Organizations: Research on Homosexuality and the Workplace. Sociology Compass, 5, 551-563. doi: 10.1111/j.1751-9020.2011.00392.x

Recebido: 17/12/2015

$1^{a}$ revisão: 28/03/2016

Aceite final: 31/03/2016 